the North Atlantic sea-bed, which for years, if not all but overlooked, certainly do not appear to have received from zoölogists the full credit which they undoubtedly deserved: geologists and palæontologists were evidently loth to abandon an hypothesis which in many respects suited their requirements.

However long truth may remain dormant, it must eventually assert itself in science as in all other matters, and the advancing strides of Biology and Geology soon demanded that such problems should be definitely and conclusively solved, and that the depths of the sea also should be carefully searched for the missing links of evidence requisite to complete their respective chains of reasoning. This was not felt to be the case in England alone; already in Scandinavia we find the savants of Norway and Sweden working with their slender means in the right direction, and assisted by their Governments with a hearty good-will and determination which could not fail to ensure valuable results, such as have already been brought forward by Sars, Nordenschjold, Torrell, and others.

In England, men of science, equally impressed with the importance of this inquiry, wished, with an honourable pride, to see that the country which had so long claimed the empire of the sea, should, in a question of so purely marine investigation, do something worthy of herself; and, being fully alive to the impossibility of doing so without the aid of the Government, applied themselves first to the task of procuring such assistance. Since it is an acknowledged but melancholy fact, that science does not in England either obtain the high position in society, or the influence with the ruling powers of the country which is accorded to it on the Continent in general, it is a subject for congratulation that the urgent appeals made to the Government should have in this instance proved so successful; and after the Government had provided the ships and equipment necessary for the expeditions of last year and this, it is a further subject for congratulation that the direction of these scientific explorations should have been entrusted to such able men as Dr. Carpenter, Prof. Wyville Thomson, and Mr. Gwyn Jeffreys, who constitute the present committee.

The expedition of last year being the first of its kind, had, as might be anticipated, many difficulties to contend with; the ship itself, besides starting at a late season of the year, was ill suited to the undertaking, was provided with but extremely inefficient winding machinery, imperfect appliances and instruments, and moreover, the observers and their assistants had, as it were, to serve an apprenticeship in the management of such operations.

This year, besides being fortunate in securing unusually favourable weather during the major part of the operations, all the above-mentioned difficulties had been provided against; whilst, at the same time, the experience'gained during the last year's cruise contributed very greatly to the complete success of the expedition as a whole.

As yet, it would be premature to attempt any description of the results of these explorations, for the Report which was commerced at the meeting of the Royal Society last Thursday is not yet concluded, but is to be continued at its next meeting; sufficient, however, has been already brought forward to prove satisfactorily the great importance of the data obtained to science in general.
Besides corroborating, and in some respects correcting the conclusions deduced from the operations of the last year's expedition, many new facts and observations have been collected, whilst the supply of specimens and materials for examination which have been brought home will no doubt give full occupation to the members of the committee for some time to come, besides obliging them to bring to their assistance the services of the physicist, chemist, and mine ralogist, each in their several departments.

The practicability of exploring even the deepest portions of the ocean bed may now be considered to be fully established; the conclusive proofs brought forward showing the existence of warm and cold areas of the deep-sea bottom, in close proximity to one another, each inhabited by its distinct and characteristic fauna, is as surprising as it is important in its scientific bearings, and particularly in its relations to geology and palæontology; whilst the investigations into the temperature of the different ocean zones, and the nature of the gases contained in the seawater at various depths, are intensely interesting and suggestive.

The question as to the existence of an azoic ocean zone at any depth, must now be regarded as finally settled in the negative. The hypothesis which appeared to Edward Forbes to be warranted by all the data which the science of his day could supply, must now be abandoned; it is certain, however, that all who knew him will do his memory the justice of believing that, were he now alive, so far from regretting the necessity of withdrawing a suggestion which appeared to explain several important points in science now once more involved in obscurity, he would have been the first of the converts to the views now proved to be more correct, and the first to congratulate the members of the deep-sea dredging committee upon so successful and brilliant a termination of their labours.

\section{DAVID FORBES}

\section{PHYSICAL METEOROLOGY}

\section{I.-ITS PRESENT POSITION}

$\mathrm{T} T$ is a well-known remark of the historian of science that our progress in astronomy has been made in exact accordance with certain laws which regulate the advancement of knowledge. Neither the march of the sun by day, nor that of the moon by night, is more rigidly surrounded and circumscribed by law than the march of that intellect which has successfully interpreted celestial motions.

We had first of all an observing age. Thousands of years ago in the plains of the East we had astronomers who, albeit with imperfect instruments, lacked neither zeal nor intelligence in their nightly study of the stars. Many of their theoretical ideas were untenable, nay, even absurd, but yet they served to bind together into a formal law the mass of observations which their nightly industry collected.

And so step by step our knowledge of celestial motions progressed, until it culminated in the discoveries of Copernicus and Kepler; and we were presented at last with a bird's-eye view of the solar system, taken, as it were, from without, in which that which appears to be, finally gave place to that which is. Thus the first stage was passed, and astronomers had now another question to put to the universe: it was no longer What are the real motions of 
the planets? but rather, Why do they move in orbits which we know to be ellipses having the sun in one of the foci? Hardly had this question been put, when a great genius answered it. The immortal Newton told us that the same law which regulates the motions of the planets round the sun, and that of the moon round the earth, determines also the path of a stone thrown by the hand, or the velocity of an apple falling from a tree.

One law was shown to hold throughout, and the expression of that law having been obtained, we were easily led to the third stage in the development of astronomy.

The problem was now-from our knowledge of the present places and motions of the heavenly bodies, and of the laws which regulate these, to determine their future places. In fact, the last or prophetical stage of the science had now been reached, and accordingly we had a race of prophets who compiled our nautical almanacs, culminating in two great prophets-one French and one English-who told us where to look for Neptune.

Thus in the most complete branch of physical inquiry there have been three stages of development. We have, first, the observational stage, the object of which was to discover the real motions of the planets of our system; next, we have the stage of generalisation, assigning the mechanical laws regulating these motions; and, lastly, we have the stage of deduction, which, from a knowledge of the places and laws of motion of the heavenly bodies, predicts their future courses.

Each of these $e_{s}$ stages had its own peculiar difficulty to encounter. That in ascertaining the actual motions of the heavenly bodies consisted in the fact that oux point of view is a movable one, and it was only when this had been surmounted that the true explanation was obtained. Again, the difficulty in the generalisation accomplished by Newton consisted in recognising that the planets in their orbits are subject to the same mechanical laws which regulate motions on the earth's surface, and in ascertaining and applying these laws; while, again, the difficulty in the third or deductive stage was an analytical one, for it was necessary to possess a method of analysis sufficiently powerful to calculate the motions of a set of bodies mutually attracting one another.

Now these historical facts, connected with the progress of astronomy, are of very great value to us, especially with reference to those other branches of science not so far advanced. We have, as it were, given us a standard of growth and development, and by measuring the younger child against the elder, we may be able to know the exact advancement of our latest born, and also the course of discipline best calculated to ensure a vigorous growth. It is by this astronomical standard that I now wish very briefly to measure what has been done in meteorology, and during these remarks I may perhaps venture to suggest a course of diet and discipline. But here, alas! there is little advancement to chronicle: the first stage of progress-the observational one-is yet very incomplete; for, viewing meteorology as that science which treats of the physics of the earth's surface, and more particularly of the atmosphere-its motion, and its physical properties, it must be acknowledged that these are very imperfectly known. At the same time it must be owned, that there are very serious diffculties in the way of obtaining this knowledge, more and greater perhaps than there were in obtaining the true motions of the heavenly bodies.

It is not because, as in astronomy, our point of view is a movable one; but rather that we are so mixed up with the earth and its atmosphere, and the motions of the latter are on so large a scale, that we find the greatest possible difficulty in grasping their true import. We are like a soldier in the' midst of a great battle, who can give but a very poor and partial account of it, attaching, as he does, undue importance to those passages of arms with which he is most concerned, and ignorant, as he must be, of the general plan of the whole. What is wanted is a bird's-eye view of the atmosphere, such as it might appear to the inhabitants of the moon, who enjoy peculiar advantages in studying the physical features of our earth, just as we do with respect to the surface of our satellite. But there is another difficulty, at least in oceanic regions. Here the scientific worker is very much in the same position as the Jews of old when rebuilding their temple, that is to say, he must work with the one hand and fight with the other, especially when there is any great commotion going on.

The commander of a vessel during a cyclone must first of all look after his vessel, and then, if he has any time to spare, it may be devoted to his barometer and thermometer. Indeed, whether on sea or land, the grand and interesting phenomena of nature carry in their train so much that is overwhelming, that the mind of the observer is not unfrequently unfitted for calm investigation. There is still a third difficulty, and that is the great improbability (despite the perseverance and industry shown by Glaisher and other meteorologists) of ever obtaining by observation a very complete knowledge of the upper regions of the earth's atmosphere.

So much for the difficulties in the way of observing, and now one word with regard to the instrumental means at our disposal. Of late years these have been greatly improved, and one of the most notable achievements in this way is the anemometer of Dr. Robinson, by means of which we can record continuously the horizontal velocity and direction of the wind. Another is the application of photography to meteorological observations, so successfully advocated and extended by the present distinguished President of the Royal Society, by means of which we obtain a continuous record of the pressure, temperature, and hygrometric condition of the air. Again, by means of certain electrical appliances due to Sir C. Wheatstone and others we may place our instrument, whatever it be, at the top of a mountain, or at the bottom of the sea, or in some equally inaccessible region, while the record of the instrument so placed may be read in the quiet and comfort of our own studies. Thus, instrumentally we are well equipped and rapidly improving, but the observations as yet made with complete instruments are very few indeed.

I come now to a very important point. Has the best use been made of the observations already obtained? Of course we all know that there has been a deplorable want of co-operation among observers, as well as of system in making their observations; but we may hope that, through the meteorological offices and societies established in all civilised countries of the world, a greater amount of method will by degrees be cotained. There is, however, something more than all this, and 
I have taken advantage of the late meeting of the British Association, at Exeter, to bring the subject before meteorologists. It appears that the general term meteorology embraces two entirely distinct subjects, one of these having reference to physiology, while the other forms a branch of physical research.

The object of the one is to study the connexion between atmospheric conditions, and the health of such organisms (animal and vegetable) as are subjected to these conditions; while the other or physical question is particularly concerned with the movements of the earth's atmosphere, and with the causes thereof.

On both of these important branches we are in almost entire ignorance. With respect to the first, the amount of vapour present in the air is without doubt a very important element of climate, inasmuch as this affects in a maxked manner the skin of the human body, and the leaves of plants; but'I am not aware that it has yet been determined by the joint action of naturalists and meteorologists what is the precise physical function expressing proportionally the effect of moisture upon animal and vegetable life. Is it simply relative humidity? or does not a given relative humidity at a high temperature have a different effect from that which it has when the temperature is low? There is, in fact, an absence of information as to the precise physical formula which is wished by physiologists, as expressing the effect of moisture upon organic life.

If we come in the next place to consider the physical branch of meteorology, or that which regards the motions of the earth's atmosphere, this is almost as far behind. The explanation of the trades and anti-trades is the one great generalisation which we have accomplished. Certain laws regarding cyclonic storms have lately been discovered; but to this day we are in ignorance of that exact motion of air which constitutes a cyclone, some holding that the motion is entirely rotatory, while others maintain that there is a considerable indraught of air from the circumference to the centre. Again, there is no fact better established than the diurnal movements of the barometer; but what is the motion of air or its constituents implied by them is still a point open to dispute. Now, these are both matters of fact, and there must be some reason why we know so Iittle about them. Nothing, of course, could be known until the instrumental difficulties of the problem had been surmounted, and a suitable anemometer constructed; but now, we have good instruments, and have begun; to make good observations. What, then, is the remaining drawback? I believe it is to be found in the fact that while instrumental appliances and observations have progressed, methods of reduction, which naturally lag behind observations, have not yet progressed, but are only just beginning to move. Those hitherto in use combine the physiological with the physical element,- they are a cross between the two, and are subject, I venture to say, as all such crosses are, to the general law of barrenness. Still not much time has been lost, for in the dark ages of few and bad observations it would have been useless to divide the meteorological field: meteorology, then, might be likened to one of those organisms of very low development that had just begun to exhibit the slightest possible tendency to split into two; the application of the knife would then have beein premature : but now it may be used with adyantage, and the one half allowed to rish into the arms of physiology, while the other seeks the embrace of physical research. In plain language, if we want to obtain physiological results we must reduce our observations with especial reference to physiology, while if physical results be desired, they must be reduced with especial reference to physical laws.

I must, however, reserve for another article a description of a method of reduction having this latter object in view.

BALFOUR STEWART

\section{PREHISTORIC TIMES}

Prehistoric Times, as illustrated by Ancient Remains, and the Manners and Customs of Modern Savages. By Sir John Lubbock, Bart., F.R.S., \&c. Second Edition. (London, 1869: Williams and Norgate.)

WE may be pardoned for not being cosmopolite enough to judge books without any regard to their nationality. Too often, though Englishman may have contributed much to some important subject, no systematic English treatise sums up the evidence, so that our students have to depend too much on foreign books of reference. On the present subject of prehistoric archæology, however, it is satisfactory that we have, in Sir John Lubbock's work, not only a good book of reference, but the best. Its well-known plan and argument need not be re-stated here, but it has to be pointed out that the present edition contains much important new matter, especially in the chapters relating to the Stone Age, Megalithic monuments, Cave-men, and the condition or modern savages.

It is a marked character of the recent researches in prehistoric archæology, and it is one of the reasons which justify the reception of the subject as a department of positive science, that the facts disclosed lend themselves to generalisations of a thoroughly scientific character; and that, moreover, when the generalisations are once made, new facts drop in and find their places ready. Various subjects discussed in the present work illustrate this: take, for instance, the stone-implement question. The finding of flakes, scrapers, spear-heads, \&c. in different parts of the world, justified a general surmise that the Stone Age had once prevailed in all inhabited districts. A few years ago, however, there were regions whence stone implements seemed hardly forthcoming. India appeared to have none, but when properly looked for they proved abundant, as witness Mr. Bruce Foote's paper in the Transactions of the Norwich Congress of 1868 . Africa aiso seemed almost outside the Stone Age world; but now the finding of stone implements in South Africa, and even legends of their use, give the primal Stone Age possessions there as elsewhere. No sooner, too, were the rude implements of the Drift type thoroughly recognised in the valley of the Somme, than it came into notice that such had long before been collected in England without knowledge of their special importance; and now Spain and India, and other districts, furnish specimens which come under the same class. So it was with the art of firemaking by friction of pieces of wood. Over most of the world, savage or civilised, the traces of its early prevalence were sufficient to justify its being generalised on as one of man's primitive arts. But there were some exceptional cases, as in Tasmania. where the natives were said to 